\title{
The influence of addiction risk on nursing students' expectations of patients' pain reports: A clinical vignette approach
}

\author{
Paula C Miceli MSc, Joel Katz PhD C Psych
}

PC Miceli, J Katz. The influence of addiction risk on nursing students' expectations of patients' pain reports: A clinical vignette approach. Pain Res Manage 2009;14(3):223-231.

OBJECTIVE: To examine the influence of addiction risk (substance abuse history $[\mathrm{SAH}]$ ) and pain relief (PR) on nursing and non-nursing students' perceptions of pain in a postoperative vignette patient.

METHODS: Using a $2 \times 2$ design, the independent variables SAH (present/+, absent/-) and PR (adequate, little) were varied systematically to produce four vignettes. Participants were randomly assigned to receive one of the four vignettes that described a 45-year-old man after a total hip replacement. Participants rated the vignette patient's experienced and reported pain intensity (PI) on a $0 \mathrm{~mm}$ to $100 \mathrm{~mm}$ visual analogue scale and addiction risk on a $0 \mathrm{~mm}$ to $100 \mathrm{~mm}$ visual analogue scale. A pain congruence $(\mathrm{PC})$ score was calculated $(\mathrm{PC}=$ reported $\mathrm{PI}-$ experienced $\mathrm{PI})$, and was interpreted as congruent $( \pm 2 \mathrm{~mm})$ or incongruent $(+2 \mathrm{~mm}$ to $+100 \mathrm{~mm}$ for expected pain over-reporting; $-2 \mathrm{~mm}$ to $-100 \mathrm{~mm}$ for expected pain under-reporting).

RESULTS: Responses from undergraduate nursing $(\mathrm{n}=89)$ and non-nursing $(\mathrm{n}=88)$ students were analyzed. The estimated addiction risk was significantly lower in nursing (14\% to $45 \%$ ) versus non-nursing students (50\%). Nursing students' mean PC scores were not significantly altered by SAH alone. Expectations of pain over-reporting were observed under conditions of SAH+/adequate PR, but not SAH+/little PR. In non-nursing students, $\mathrm{SAH}$ and PR were significant and independent factors influencing mean $\mathrm{PC}$ scores in the direction of pain over-reporting.

CONCLUSION: Under most conditions, nursing students expected pain under-reporting by the postoperative vignette patient. However, nursing students did expect pain to be over-reported when addiction risk was high and PR was adequate. These data suggest that nursing students' expectations regarding pain over- and under-reporting were sensitive to perceptions of addiction risk, but involved additional factors (eg, level of PR).

Key Words: Addiction; Iatrogenic; Nursing students; Opioids; Postoperative pain; Pseudoaddiction

\section{Influence du risque de toxicomanie sur les prévisions des étudiants en soins infirmiers vis-à-vis de la douleur autorapportée par les patients : Approche par cas cliniques}

OBJECTIFS : Vérifier l'influence du risque de toxicomanie (antécédents de toxicomanie [AT]) et du soulagement de la douleur (SD) sur les perceptions d'étudiants de soins infirmiers et d'autres programmes quant à la douleur dans une étude de cas en postopératoire.

MÉTHODES : À l'aide d'un modèle $2 \times 2$, les variables indépendantes AT (présents/+, absents/-) et SD (adéquat, minime) ont été appariées systématiquement pour générer quatre vignettes. Les participants ont été assignés aléatoirement à l'une de ces quatre vignettes qui décrivaient un homme de 45 ans ayant subi une chirurgie pour prothèse totale de la hanche. Ils ont classé l'intensité de la douleur (ID) manifestée et rapportée par le patient sur une échelle analogique visuelle de $0 \mathrm{~mm}$ à $100 \mathrm{~mm}$ et le risque de toxicomanie sur une échelle analogique visuelle de $0 \mathrm{~mm}$ à $100 \mathrm{~mm}$. Un score de congruence de la douleur $(C D)$ a été calculé $(C D=$ ID rapportée ID éprouvée) et a été jugé congruent $( \pm 2 \mathrm{~mm})$ ou non congruent $(+2 \mathrm{~mm}$ à $+100 \mathrm{~mm}$ pour les prévisions d'autorapports de douleur amplifiée; $-2 \mathrm{~mm}$ à - $100 \mathrm{~mm}$ pour les prévisions d'autorapports de douleur minimisée).

RÉSULTATS : Les auteurs ont analysé les réponses des étudiants de soins infirmiers $(n=89)$ et d'autres programmes $(n=88)$. Le risque estimé de toxicomanie a été significativement plus faible pour les étudiants en soins infirmiers (14\% à $45 \%$ ) que pour les étudiants d'autres programmes (50\%). Les scores moyens de CD des étudiants de soins infirmiers n'ont pas été significativement modifiés par les AT seuls. Les prévisions d'autorapports de douleur amplifiée ont été en lien avec les critères AT+/SD adéquat, mais non avec les critères $\mathrm{AT}+/ \mathrm{SD}$ minime. Pour les étudiants d'autres programmes, les AT et le SD ont été des facteurs significatifs et indépendants qui ont influé sur les scores moyens de CD en faveur d'autorapports de douleur amplifiée. CONCLUSION : Dans la plupart des cas, les étudiants de soins infirmiers se sont attendus à des autorapports de douleur postopératoire minimisée par le patient. Toutefois, ils s'attendaient à ce que la douleur rapportée soit amplifiée lorsque le risque de toxicomanie était élevé et que le SD était adéquat. Ces données donnent à penser que les attentes des étudiants en soins infirmiers au sujet des autorapports de douleur amplifiée ou minimisée coïncidaient avec les perceptions du risque de toxicomanie, mais tenaient compte d'autres facteurs (p. ex., de degré de SD).

postoperative pain can be understood as belonging to three major categories. The first category, patient-related characteristics, includes factors such as patient unwillingness to inform the nursing staff about their pain (10) and misconceptions about the risk of addiction to opioids. The second category, health professional characteristics, includes factors such as misconceptions about the prevalence of addiction to opioid analgesics $(10,11)$, negative evaluations or labelling of patients with intractable pain (12), and professionals' beliefs that patients overstate their level of pain intensity due to addiction or tolerance to opioid analgesics (13). Finally, the category of organizational or situational characteristics includes the difficulties of implementing guidelines that integrate scientific evidence into clinical practice
$\mathrm{M}$ edical intervention to alleviate illness, infection or physical dysfunction often involves the use of invasive surgical procedures, and tissue damage and pain are expected outcomes. Postoperative pain can range in intensity from mild to severe and, despite the use of a variety of analgesic agents, postoperative pain remains poorly managed $(1,2)$. In particular, patients report severe postoperative pain despite treatment (3), which can be associated with delays in hospital discharge (4), decreased quality of life (5) and chronic postsurgical pain (6). To date, scientific investigations have been directed toward understanding the association between undertreatment of pain and health care professionals' attitudes, beliefs, perceptions and judgment (7-9). Factors contributing to the undertreatment of 
in individual settings $(7,8)$. These factors have been noted to play an important role in the assessment of chronic pain in community (14) and primary care settings (15). Given that patient and health care professional interactions are complex, dynamic and occur moment to moment, it is likely that many factors related to the patient, health care professional and institution interact and contribute to undertreatment of pain at any given time.

The primary objective of the present study was to examine the influence of perceived addiction risk (high or low) on nursing students' perceptions of pain in a postoperative vignette patient. In particular, we were interested in testing the hypothesis that nursing students would expect the vignette patient to over-report their pain under conditions of high addiction risk. Concerns regarding the risk of opioid addiction in postoperative patients have been well documented (16), and health care professionals' attitudes and beliefs related to the risk of iatrogenic addiction have been associated with the "withholding of opioid analgesics" (1). Consequences of such beliefs and behaviours are significant - not just in terms of secondary physical harm to the patient, but also in terms of the erosion of trust in patientpractitioner and patient-institution relationships (ie, pseudoaddiction), as described in a case report (17). A $2 \times 2$ factorial design was used to influence the perception of addiction risk in the vignette patient (high or low risk). Study participants estimated the amount of pain they believed the vignette patient experienced, as well as the amount of pain they believed the vignette patient would report. The study design was derived from sociopsychological research methods; therefore, participants were intentionally not provided information regarding what the numerical pain level might be (ie, there were no absolute or 'right' levels of estimated pain). Instead, the level of agreement between the two pain ratings, which reflected the participants' own expectations of pain over- or under-reporting, were compared between the experimental groups. Pain ratings of the nursing student sample were compared with a sample of undergraduate students engaged in disciplines other than nursing to contextualize the research findings with respect to the specialized education and training in professional nursing regarding pain management.

\section{METHODS}

Before the present study began, the research protocol and participant information and consent form were reviewed and approved by the Human Participants Review Committee at York University (Toronto, Ontario) and a second local university research ethics board. The present study was conducted at three universities and one college in southwestern Ontario from 2004 to 2005. Male or female full-time undergraduate students, who were registered in a baccalaureate program at the time of the study, were 18 years of age or older, and were willing to participate and provide written informed consent were enrolled. Undergraduate students were recruited from bachelor of science nursing programs, as well as from programs not related to the direct provision of health care services (programs without clinical or health skills training). Individuals were excluded from the study if they held current registration for independent practice as a health care professional in any province or territory in Canada or another country, or had completed examinations (oral or written) offered by a regulatory body (eg, the College of Nurses of Ontario), or an equivalent examination, for the purposes of registration with a regulatory health care professional body in Canada or another country.

All students were approached during regularly scheduled classes, provided a brief verbal description of the study and given a written copy of the consent form. Students who consented to participate were assigned a study number for identification and randomization purposes. The randomization code was generated for each institution where recruitment was undertaken using www.randomization.com, accessed February 11, 2005. Each participant was provided with an envelope containing a vignette, instructions and two questionnaires. The brief, one-page vignette described the progression of a 45-year-old man undergoing surgical replacement of the hip joint from hospital admission to convalescence on a surgical ward (Appendix 1). All vignettes included a general narrative, with modifications in the wording of three lines of text according to the randomization code. Study participants, who were not aware of multiple versions, read one version of the vignette, and then were instructed to complete the questionnaires. Before use, the vignette was reviewed for representativeness by a research nurse with 10 years of experience in a postanesthetic care unit, as well as a practicing anesthesiologist. Questionnaires were returned in person, by campus mail or by postal mail. One instructor offered course credit for participation and students were informed of the course credit before consent (approximately 30 participants).

\section{Independent and dependent variables}

The primary objective was to examine the influence of perceived addiction risk (high or low) on nursing students' perceptions of pain in a postoperative vignette patient. The present study used a $2 \times 2$ between-subject experimental design to induce high-versus low-risk conditions of opioid addiction, and examine the level of agreement (ie, congruence) of participants' estimates of the vignette patients' experienced pain and reported pain. Two independent variables were used in the present study, which were derived, in part, from a case report describing pseudoaddiction (17). The first independent variable was substance abuse history (SAH) (present [SAH+] or absent [SAH-]), which was included to induce high and low perceived addiction risk in the vignette patient. The second independent variable was the level of pain relief ( $\mathrm{PR})\left(\mathrm{PR}_{\text {adequate }}\right.$ or $\left.\mathrm{PR}_{\text {little }}\right)$, a composite descriptive variable involving a statement of the adequacy of PR achieved (adequate or little relief), the number of requests for additional opioid analgesics during the time interval between doses (no request or two requests) and the description of the vignette patients' experience of the following side effects: nausea, anxiety and difficulty sleeping (present or absent). This second variable was introduced to simulate conditions in which the vignette patient demonstrated an adequate or poor clinical response to the analgesic treatment. The $2 \times 2$ design created four experimental conditions: $\mathrm{SAH}+$ and $\mathrm{PR}_{\text {adequate }}, \mathrm{SAH}+$ and $\mathrm{PR}_{\text {little' }}$, $\mathrm{SAH}-$ and $\mathrm{PR}_{\text {adequate }}$, and $\mathrm{SAH}-$ and $\mathrm{PR}_{\text {little }}$.

Participants were asked to perform two sequential assessments of the vignette patient's pain intensity: the severity of the pain experienced by the patient (experienced pain intensity [EPI]) and the severity of the pain reported by the vignette patient (reported pain intensity $[\mathrm{RPI}]$ ). Pain intensity was assessed using a visual analogue scale (VAS), consisting of a $100 \mathrm{~mm}$ horizontal line with the two ends bound by the anchors 'no pain' on the left and 'worst pain imaginable' on the right (18). The VAS is a simple 
and efficient measure of pain intensity that has been used widely in research settings (19). The distance in millimetres from the low end of the VAS to the participant's mark was used as a numerical index of pain intensity. A pain congruence (PC) score was calculated by subtracting the EPI from the RPI (PC = RPI - EPI) for each research subject. Historically, congruence between pain ratings has been used in a clinical setting to describe the level of agreement between patient pain reports and an observing health professionals' estimates of a patients' pain $(20,21)$. In contrast, PC scores in the present study reflect the level of agreement between raters' estimates of the vignette patients' reported pain and experienced pain. A congruent estimate is represented by a PC score of $0 \pm 2 \mathrm{~mm}$, which occurs when the RPI equals the EPI, taking into account reasonable measurement error $( \pm 2 \mathrm{~mm})$. An incongruent estimate is any deviation from 0 , which may represent either an expectation of pain over-reporting (RPI greater than EPI) or pain under-reporting (RPI less than EPI).

The rationale for the present study design and data interpretation was derived from social-psychological research methods that attempt to uncover the presence of latent bias (eg, expectations) regarding others' behaviour. First, all estimates of experienced pain by the study participants were considered to be acceptable and legitimate estimates and did not require validation with an external or 'real-world' standard. The clinical vignette did not provide cues regarding 'normal' or 'average' pain ratings in this context, or state a numerical pain rating (Appendix 1). Instead, cues regarding numerical pain ratings in the vignette were intentionally kept undefined to permit assessment of participants' perceptions that would be guided by internally based judgments, which may contain latent biases, instead of judgments informed by an externally driven standard in the vignette. Second, the data-analytic approach was to determine whether study participants viewed the vignette patient as reporting levels of pain that were congruent (ie, similar) or incongruent (ie, dissimilar) to the previously estimated level of pain experienced by the vignette patient. Using this model, pain incongruence reflects a study participant's internally driven expectation that what the patient is experiencing is not what they tell staff. Instead, the participant expects the patient to modify or adjust their pain report in a way that differs from their experience, in a direction that either under- or over-reports their pain. When pain ratings are congruent, the interpretation is that the participant expected the patient to report exactly the same level of pain as they experienced. The extent of congruence was compared across experimental conditions of high or low addiction risk to determine whether the participants' expectations about pain differed under conditions of high addiction risk. While this method is designed to tap into intrinsic psychological factors (eg, attitudes, beliefs and perceptions) involved in the participants' expectation of incongruence, it was not designed to identify the nature of the psychological factors. The psychological factors are not elucidated in the present study; therefore, the term 'expectation' is used. Whatever psychological factors are involved (eg, thoughts, ideas, perceptions, beliefs and attitudes), the respondents' expectations of congruence or incongruence between the two pain ratings represent the convergence of one or more of these factors. Furthermore, from a psychological perspective, if this expectation is present, it is unknown whether it is 'conscious' or beyond conscious awareness. As such, the term 'expectation' is not intended to convey the level of consciousness in the psychological process underlying the pain congruence construct. It is speculated that internally driven judgments or expectations regarding whether patients adjust pain reports may influence the treatment offered by health professionals, especially with respect to opioid management.

Given the high priority of inducing different levels of addiction risk across study conditions (eg, to measure its effect on the congruence of pain ratings), a measure of the perception of addiction risk was included as a dependent variable. In the past, Allcock and Toft (11) assessed perceived addiction risk using categorical estimates of risk (less than $1 \%, 1 \%$ to $15 \%, 16 \%$ to $25 \%$, etc); however, given our concern that this scale may not possess sufficient measurement sensitivity, a $100 \mathrm{~mm}$ VAS was constructed, bounded by the anchors 'no risk' on the left and 'highest possible risk' on the right. Participants were asked to "estimate the risk of addiction in the post-operative patient" by placing a slash (/) on the $100 \mathrm{~mm}$ horizontal line. The distance in millimetres from the low end of the VAS to the participant's mark was considered to be a numerical index of addiction risk. To ensure similar knowledge of the definition of addiction across study participants, the questionnaire included the definition of addiction as stated in the Diagnostic and Statistical Manual of Mental Disorders, 4th Edition (DSM-IV) (22).

All participants were asked to provide demographic information including age, sex, number of years of postsecondary education, program and year of study. Participants were also asked to estimate the number of hours spent in practical training as a trainee in a community, hospital or other clinical setting; in practical training in a postoperative setting; and as an employee or volunteer in a clinical, hospital or other community health care setting (aside from practicum hours). Personal or vicarious experiences with surgery (number of surgeries undergone, longest duration in hospital in days, and the number of surgeries undergone by significant others as well as their duration in hospital in days) were also reported by study participants.

\section{Statistical approach and analysis}

The study objective was to examine the influence of suspected addiction risk (high or low) on PC scores in the nursing (NRS) and non-nursing (UGS) student groups using a general linear model (23). To be congruent with the data collection process, the statistical analysis plan placed a high priority on the inclusion of both groups in one statistical model. First, perceived addiction risk scores were examined using a 2 (GROUP: UGS/ NRS $) \times 2($ SAH: $+/-) \times 2($ PR: adequate/little $)$ ANOVA to confirm that the study manipulation $(\mathrm{SAH}+$ or SAH- condition) differentiated high addiction risk from low addiction risk conditions. Given that the nursing students differed considerably in their levels of training and practical experience, firstyear nursing students (FYN) were distinguished from senior-year nursing students (SYN) and entered into a separate ANOVA (2 [YEAR OF STUDY: FYN/SYN] $\times 2$ [SAH: $+/-] \times 2$ [PR: adequate/little]) model to compare mean VAS addiction risk ratings across FYN and SYN students. Next, PC scores were examined separately in the nursing student group using a 2 (GROUP: FYN/SYN) $\times 2(\mathrm{SAH}:+/-) \times 2(\mathrm{PR}$ : adequate/little) ANOVA, and in the non-nursing student group using a $2(\mathrm{SAH}:+/-) \times 2$ (PR: adequate/little) ANOVA. All data are expressed as mean \pm SEM. When significant 


\begin{tabular}{|c|c|c|}
\hline Variable & $\begin{array}{l}\text { Nursing group } \\
(n=89)\end{array}$ & $\begin{array}{l}\text { Non-nursing } \\
\text { group }(n=88)\end{array}$ \\
\hline Sex, female/male, $n$ & $87 / 2$ & $68 / 20$ \\
\hline Age, years & $23.8 \pm 0.6$ & $22.5 \pm 0.4$ \\
\hline Program year & $2.2 \pm 0.1^{*}$ & $3.0 \pm 1.0$ \\
\hline Postsecondary education, years & $3.0 \pm 0.3$ & $3.2 \pm 0.2$ \\
\hline Practical program training completed, $\mathrm{h}$ & $455.4 \pm 52.6^{*}$ & $13.9 \pm 6.5$ \\
\hline $\begin{array}{l}\text { Practical program training completed } \\
\text { (postoperative setting), } \mathrm{h}\end{array}$ & $123.7 \pm 11.4^{*}$ & $4.2 \pm 2.6$ \\
\hline $\begin{array}{l}\text { Classroom hours in postoperative pain } \\
\text { assessment/management }\end{array}$ & $23.6 \pm 4.6^{*}$ & $5.0 \pm 1.2$ \\
\hline $\begin{array}{l}\text { Volunteer or employment in a health } \\
\text { care setting, } \mathrm{h}\end{array}$ & $398 \pm 135.2^{\star \star}$ & $119 \pm 37.5$ \\
\hline
\end{tabular}

All data are reported as mean \pm SEM unless otherwise specified. ${ }^{*} P<0.0001$;

${ }^{*} P=0.05$ (Welch $F$, nursing group versus non-nursing group)

interaction effects were noted, a simple effects analysis with least significant difference (LSD) (eg, examining one variable within each level of the other variable) was used to unpack the effects. Where applicable, analysis of significant main effects was also conducted using LSD. Demographic and educational variables in the nursing students were compared using univariate ANOVA (Welch F) with post hoc Tukey tests. Demographic and educational variables were compared among nursing and non-nursing student participants using univariate ANOVA (Welch F). Mean estimated addiction risk was compared among different levels of nursing training using a one-way ANOVA with LSD. The level of statistical significance was set at $\alpha=0.05$.

\section{Study participants}

\section{RESULTS}

Participants were recruited from four postsecondary institutions in southwestern Ontario during the 2005 winter term. Approximately 470 students undertaking full-time undergraduate day classes at three universities and one college were asked to participate in the study, and $45 \%$ of students $(n=212)$ consented. Of 212 individuals who consented to participate, 179 (84\%) completed and returned the questionnaires. The overall study response rate was 38\% (179 of 470). The final sample for the nursing group included students in bachelor of science degree nursing programs ( $\mathrm{n}=89 ; 99 \%$ women) and the non-nursing group was comprised of undergraduate full-time students ( $\mathrm{n}=88 ; 77 \%$ women) in disciplines unrelated to direct health care service delivery, including kinesiology $(n=29)$, psychology $(n=28)$, health and society $(n=22)$, and other disciplines (biology, $n=2$; chemistry, $n=1$; education, $n=1$; social science, $\mathrm{n}=1$; sociology, $\mathrm{n}=1$; theatre, $\mathrm{n}=1$; unspecified, $\mathrm{n}=2$ ). Two data points from undergraduate non-nursing students were excluded due to self-reported training in postoperative pain management (more than $100 \mathrm{~h}$ ).

Demographic and educational variables of the nursing and non-nursing samples are given in Table 1 . As expected, participants in the nursing group reported significantly more training hours in health care and postoperative settings, as well as a significantly greater number of hours in didactic pain assessment and management training compared with the non-nursing group
$(\mathrm{P}<0.0001)$. Participants in the nursing group also completed a significantly greater number of volunteer or employment hours in a health care setting compared with the non-nursing group $(\mathrm{P}<0.05)$. The two groups were similar with respect to personal characteristics (eg, age, postsecondary education; $\mathrm{P}>0.05$ ).

There were no significant differences between the nursing and non-nursing groups in terms of mean number of lifetime surgeries $(0.7 \pm 0.1$ versus $0.6 \pm 0.1)$, number and percentage who reported one or more personal experiences of surgery (33 [37\%] versus 27 [31\%]), longest duration in hospital (4.3 \pm 1.1 days versus $3.4 \pm 0.8$ days), mean number of lifetime surgeries of significant others $(1.4 \pm 0.1$ versus $1.3 \pm 0.1)$, longest duration in hospital of a significant other $(14.1 \pm 3.6$ days versus $33.5 \pm 22.4$ days) and number and percentage who reported one or more vicarious experiences of surgery (67 [75\%] versus $65[73 \%])$.

Given that data collection took place at several training institutions and spanned different stages of training (first year, third year and final year nursing students), self-reported demographic and educational variables were compared between two subgroups of nursing participants (FYN [ $\mathrm{n}=48]$ versus SYN $[\mathrm{n}=41]$ students). Both groups were similar with respect to age, number of previous surgeries, duration of previous postoperative hospital admissions, number of previous surgeries of significant others, duration of hospital admissions of significant others and classroom training in pain management (data not shown; $\mathrm{P}>0.05$, all comparisons). Overall, students in their senior year of nursing training had completed significantly greater experiential training compared with FYN students, including more practical training hours in health care settings (FYN $109 \pm 7.8 \mathrm{~h}$ versus SYN $867.3 \pm 68.3 \mathrm{~h}, \mathrm{P}<0.001$ ) and more practical training hours in postoperative settings (FYN $68.5 \pm 6.1 \mathrm{~h}$ versus SYN $183.1 \pm 18.8 \mathrm{~h}, \mathrm{P}<0.001$ ).

\section{Ratings of addiction risk in the undergraduate nursing and non-nursing groups}

The primary objective of the present study was to examine students' perceptions of pain in a postoperative vignette patient under conditions of high or low perceived opioid addiction risk. Thus, it was first examined whether study participants perceived different levels of addiction risk (high versus low) across the $2 \times 2$ study conditions. Using a 2 (GROUP: UGS, $\mathrm{NRS}) \times 2(\mathrm{SAH}:+/-) \times 2(\mathrm{PR}:$ adequate/little $)$ ANOVA, a significant interaction effect of GROUP $\times \mathrm{SAH}(\mathrm{F}[1,171]=4.0$, $\mathrm{P}=0.046$ ) was observed, indicating that both the GROUP and SAH factors influenced addiction risk but the effect differed across the levels of independent variable (Table 2). The main effect of GROUP (F $[1,171]=27.4, \mathrm{P}<0.0001)$ and SAH $(\mathrm{F}[1,171]=17.2, \mathrm{P}<0.0001)$ were significant, but the main effect of PR was not statistically significant $(F[1,171]=0.277$, $\mathrm{P}=0.60$; adequate relief $45.3 \pm 2.8 \mathrm{~mm}$ versus little relief $47.4 \pm 2.7 \mathrm{~mm}$ ). Analysis of the GROUP $\times \mathrm{SAH}$ interaction effect revealed that mean addiction risk scores were significantly greater in the non-nursing group than in the nursing group in both $\mathrm{SAH}+(60.9 \pm 3.8 \mathrm{~mm}$ versus $48.2 \pm 4.0 \mathrm{~mm}$, $\mathrm{P}=0.024)$ and $\mathrm{SAH}-$ conditions $(52.5 \pm 4.0 \mathrm{~mm}$ versus $23.9 \pm 3.9 \mathrm{~mm}, \mathrm{P}<0.0001$, respectively). Within-group comparisons of mean addiction risk scores revealed that SAH was a significant factor influencing addiction risk in the nursing group, but not in the non-nursing group. Within the nursing 
TABLE 2

Mean ratings of perceived addiction risk $(0 \mathrm{~mm}$ to $100 \mathrm{~mm}$ visual analogue scale [VAS]) in non-nursing and nursing groups*

\begin{tabular}{lll}
\hline & \multicolumn{2}{c}{ SAH variable } \\
\cline { 2 - 3 } Pain relief variable & Present & Absent \\
\hline Nursing group & & \\
$\quad$ Adequate & $46.7 \pm 5.9^{\dagger}$ & $21.6 \pm 5.6$ \\
$\quad$ Little & $49.7 \pm 5.5^{\dagger}$ & $26.2 \pm 5.2$ \\
Non-nursing group & & \\
$\quad$ Adequate & $60.4 \pm 5.4$ & $52.5 \pm 5.8$ \\
Little & $61.3 \pm 5.5$ & $52.3 \pm 5.6$ \\
\hline
\end{tabular}

Data presented as mean \pm SEM. *A significant GROUP $\times$ substance abuse history (SAH) interaction effect was observed. VAS addiction risk ratings were significantly greater in $\mathrm{SAH}+$ versus $\mathrm{SAH}$ - conditions in the nursing group $\left({ }^{\top} P<0.0001\right.$, present versus absent), but not in the non-nursing group $(P>0.05)$. Non-nursing students reported significantly greater VAS addiction risk ratings versus the nursing group $(P=0.024)$. Pain relief was not a significant factor

TABLE 3

Mean ratings of perceived addiction risk $(0 \mathrm{~mm}$ to $100 \mathrm{~mm}$ visual analogue scale [VAS]) in first-year nursing (FYN) and senior-year nursing (SYN) students

\begin{tabular}{|c|c|c|c|}
\hline \multirow[b]{2}{*}{ Year of nursing study } & \multicolumn{3}{|c|}{ SAH variable } \\
\hline & Overall & Present & Absent \\
\hline \multicolumn{4}{|l|}{ Nursing group } \\
\hline SYN & $23.8 \pm 3.8^{*}$ & $39.2 \pm 6.1$ & $11.5 \pm 5.2^{\dagger}$ \\
\hline FYN & $45.9 \pm 4.2^{*}$ & $56.8 \pm 5.1$ & $35.7 \pm 5.1^{\dagger}$ \\
\hline Non-nursing group $\ddagger$ & $56.7 \pm 2.8$ & $61.3 \pm 5.5$ & $52.3 \pm 5.6$ \\
\hline
\end{tabular}

Data presented as mean \pm SEM. *Overall VAS addiction risk ratings were significantly greater in FYN compared with SYN students. ${ }^{\dagger}$ Substance abuse history (SAH) (present or absent) was a significant factor influencing mean VAS addiction risk ratings in both FYN and SYN groups. ${ }^{\ddagger}$ Mean VAS addiction risk ratings in the non-nursing group were included to demonstrate the absence of significant influence of the SAH factor on addiction risk ratings in this group

group, mean addiction risk scores were significantly greater in the SAH+ condition compared with the SAH- condition in the nursing group $(48.2 \pm 4.0 \mathrm{~mm}$ versus $23.9 \pm 3.9 \mathrm{~mm}$, $\mathrm{P}<0.0001)$, whereas there was no significant difference in mean addiction risk scores across SAH conditions in the nonnursing group $(52.5 \pm 4.0 \mathrm{~mm}$ versus $60.8 \pm 3.9 \mathrm{~mm}, \mathrm{P}=0.133$; Table 2). In summary, non-nursing participants perceived the risk of addiction to be $50 \%$ or greater (eg, approximately one in two) across all experimental groups, and demonstrated greater mean addiction risk compared with nursing participants. However, SAH was a factor influencing mean addiction risk scores in the nursing but not in the non-nursing group.

Given that the nursing students differed considerably in their levels of training and practical experience, an ANOVA (2 [YEAR OF STUDY: FYN/SYN] × 2 [SAH: +/-] $\times 2$ [PR: adequate/little]) model was used to compare mean addiction risk ratings across FYN and SYN students. There was a significant main effect of SAH $(F[1,85]=20.7, \mathrm{P}<0.001)$ and YEAR OF STUDY $(F[1,85]=15.3, \mathrm{P}<0.001)$, which was explored using simple main effects analysis. The main effects of PR (F[1, $85]=1.0, P=0.31$ ) on mean addiction risk scores was not significant. SAH was a significant and independent factor influencing mean addiction risk ratings, with higher levels of risk

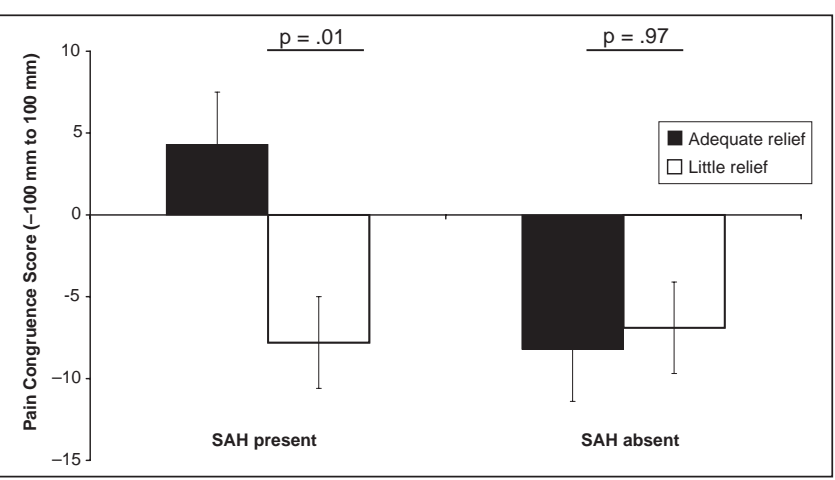

Figure 1) Mean ( \pm SEM) ratings of pain congruence (PC) scores across substance abuse history and pain relief conditions in the nursing group. Patterns of PC scores suggest a tendency toward expecting the vignette patient to under-report pain in all conditions except the condition in which substance abuse history (SAH) and adequate pain relief were present, in which there was a tendency to expect pain to be over-reported (mean PC score greater than $2 \mathrm{~mm}$ )

associated with the presence of SAH (SAH- 23.6 \pm 3.6 versus $\mathrm{SAH}+48.0 \pm 3.9, \mathrm{P}<0.001$; Table 3$)$. Year of study was also a significant and independent factor, with higher levels of risk estimated by FYN students compared with SYN students (FYN $46.3 \pm 3.6$ versus SYN 25.3 $\pm 4.0, \mathrm{P}<0.001)$. Despite the significant differences in mean addiction risk ratings between FYN and SYN students, both groups demonstrated an analogous response to $\mathrm{SAH}$ as a significant risk factor that increased mean addiction risk ratings (Table 3 ).

Influence of SAH and PR factors on mean addiction risk ratings and $\mathrm{PC}$ scores in the nursing student group Given that the nursing students perceived high versus low opioid addiction risk across the $\mathrm{SAH}+/$ - conditions, the hypothesis that nursing students would perceive the postoperative vignette patient as over- or under-reporting their pain across the $2 \times 2$ study conditions was then tested. It was noted that nursing students differed considerably in their estimates of addiction risk across different levels of training and training sites; therefore, these sites were included in the ANOVA model (2 [YEAR OF STUDY: FYN/SYN] $\times 2$ [SAH: +/-] $\times 2$ [PR: adequate/little]). There was a significant interaction effect of $\mathrm{SAH} \times \mathrm{PR}$ $(F[1,88]=4.0, P=0.05)$ that was explored using simple effects analysis. The main effects of SAH $(F[1,88]=2.4, \mathrm{P}=0.12)$ and YEAR $(F[1,88]=0.08, P=0.78)$ on $\mathrm{PC}$ scores were not significant. The main effect of $\mathrm{PR}(\mathrm{F}[1,88]=3.8, \mathrm{P}=0.05)$ was significant, but was analyzed as part of the interaction effect. Mean PC scores were significantly greater in the $\mathrm{SAH}+$ versus the $\mathrm{SAH}-$ condition when $\mathrm{PR}_{\text {adequate }}(\mathrm{P}=0.019)$, whereas there was no significant difference between the $\mathrm{SAH}+$ and $\mathrm{SAH}-$ conditions when $\mathrm{PR}_{\text {little }}(\mathrm{P}=0.73)$. Similarly, in the SAH+ condition, mean $\mathrm{PC}$ scores were significantly greater in the $\mathrm{PR}_{\text {adequate }}$ versus the $\mathrm{PR}_{\text {little }}$ condition $(\mathrm{P}=0.01)$, whereas there was no significant difference between $\mathrm{PR}_{\text {adequate }}$ and $\mathrm{PR}_{\text {little }}$ conditions in the SAHcondition $(\mathrm{P}=0.97)$ (Figure 1).

Furthermore, PC scores were negative (eg, less than $-2 \mathrm{~mm}$ ) in all conditions except $\mathrm{SAH}+/ \mathrm{PR}_{\text {adequate, }}$, for which the mean was $+4.3 \pm 3.5 \mathrm{~mm}$. These data suggest that the predominant tendency across study conditions was that nursing students expected the vignette patient to under-report pain intensity, 
with the exception of the $\mathrm{SAH}+/ \mathrm{PR}_{\text {adequate }}$ condition, in which they expected the vignette patient to over-report pain.

Comparison of the influence of SAH and PR factors on PC scores among non-nursing undergraduate students

Although the primary study objective was to examine nursing and non-nursing students' perceptions of pain in a vignette patient under conditions of high or low perceived addiction risk, the results of planned comparisons revealed that differential levels of addiction risk were induced in the nursing but not the non-nursing group. Given that the two groups responded differently to the study manipulation, it was decided not to proceed with a 2 (GROUP: UGS, NRS) $\times 2(\mathrm{SAH}:+/-) \times 2(\mathrm{PR}$ : adequate/little) ANOVA. However, the influence of SAH and PR factors on PC scores in the non-nursing group was examined using a $2(\mathrm{SAH}:+/-) \times 2(\mathrm{PR}$ : adequate/little) ANOVA. The objective of this statistical comparison was to examine whether the SAH and PR factors influenced PC scores, given that all treatment conditions were considered at $50 \%$ or greater risk of addiction. There was a significant main effect of SAH $(\mathrm{F}[1,87]=10.6, \mathrm{P}=0.002)$ and PR $(\mathrm{F}[1,87]=6.2$, $\mathrm{P}=0.014)$ on $\mathrm{PC}$ scores in the non-nursing group. With respect to the main effect of SAH, mean PC scores were significantly greater in the $\mathrm{SAH}+$ condition versus the $\mathrm{SAH}-$ condition $(14.9 \pm 2.9 \mathrm{~mm}$ versus $1.0 \pm 3.0 \mathrm{~mm}, \mathrm{P}=0.002)$. Note that the positive valence of the $\mathrm{PC}$ score in the $\mathrm{SAH}+$ condition suggested that the vignette patient's self-reported pain was expected to be distorted and over-reported compared with a neutral PC score for the SAH- condition. With respect to the main effect of PR, mean PC scores were significantly greater in the $\mathrm{PR}_{\text {little }}$ condition versus the $\mathrm{PR}_{\text {adequate }}$ condition $(13.2 \pm 3.0 \mathrm{~mm}$ versus $2.7 \pm 3.0 \mathrm{~mm}, \mathrm{P}=0.014$ ). Note that the positive valence of the $\mathrm{PC}$ score in the $\mathrm{PR}_{\text {little }}$ condition also suggested that the vignette patient's self-reported pain was expected to be distorted and over-reported compared with a neutral $\mathrm{PC}$ score for the $\mathrm{PR}_{\text {adequate }}$ condition.

\section{DISCUSSION}

Despite the availability of safe and effective analgesic agents, postoperative pain remains significantly unrelieved, which may, in part, be related to the "misunderstanding of addiction and mislabeling of patients as addicts resulting in unnecessary withholding of opioid medications" (1). Pain is a private and subjective experience (24) and clinicians are called on to view and decode tangible cues, including patients' pain behaviours and verbal reports, to inform their judgment and make decisions regarding the next steps in treatment (25). Pain assessment and treatment draw on a complex interaction between the patient and the health care professionals' attitudes and beliefs, education and training, personal experience with pain, and professional experience in caring for others in pain $(7,13,26)$. In the present study, the primary objective was to examine the influence of opioid addiction risk (high or low) on nursing students' perceptions of pain in a postoperative vignette patient. A nursing sample was chosen because in clinical practice, registered nurses spend considerable time with patients and play a pivotal role in the assessment and management of patients' postoperative pain (27).

The present study used a clinical vignette approach to uncover students' expectations regarding pain over- and under-reporting in postoperative patients. Participants first estimated the pain the vignette patient experienced and then, immediately after, estimated the pain they believed the patient would report to the treating staff. In contrast to other study designs (28), the narrative did not provide cues regarding 'normal' or 'average' pain ratings under these circumstances, nor did they provide a numerical pain rating reported by the vignette patient. Instead, the important aspect of the pain ratings was the level and direction of incongruence between the second rating (reported pain) and the first rating (experienced pain). In doing so, the method was directed toward tapping intrinsic psychological factors (eg, attitudes, beliefs and perceptions) that were involved in the participants' expectation that the second rating (reported pain) would be incongruent or congruent to the first rating. The direction of the mean PC rating reflects, on average, the participants' expectations of pain over-reporting (ie, positive ratings) or under-reporting (ie, negative ratings) in the vignette patient. Determining the nature of the psychological factors was not of primary importance in the study, but instead, the level of congruence was compared across experimental conditions to determine whether expectations about pain differed with high or low perceived addiction risk. Elucidation of the beliefs, attitudes and perceptions using questionnaires with psychometric validity may be an area for further research.

Mean addiction risk estimates in the postoperative vignette patient by undergraduate non-nursing students were more than $50 \%$ (eg, one in two). Although similar research findings have been reported in medical patients (29), these data suggest a commonly held idea in the general public that risk of addiction to opioids is likely with postoperative use. Fear of opioid addiction has been associated with patients' reluctance to report pain or use opioids (30), and these results reflect a need for continued reflection about public perceptions of risk, and the implications of these results on the practice of pain assessment and management. In contrast, perceptions of mean addiction risk in the undergraduate nursing students was significantly less than in non-nursing students and varied by stage of nursing training. Mean risk was similar among first-year undergraduate nursing $(45 \% \pm 4 \%$ risk) and non-nursing students (approximately a $50 \%$ risk), but less in nursing students with greater training and experience (15\% risk). Estimates of addiction risk in the nursing students were larger than those reported in a longitudinal study of student nurses (less than 15\%) (12). Although these results suggest that student nurses in their senior years of study reported a lower risk of addiction, the sampling methodology and study design limit the conclusions that can be drawn in this regard. Nursing student participants were recruited from three educational institutions, and differences noted between groups may be related not only to the extent of training, but also site differences, including curriculum and institutional training models. Conclusions regarding shifts in perception of risk over time in training have been addressed in longitudinal studies, and these studies have indicated that estimates of addiction risk decline with progression in training for approximately one-half of the trainees (11).

In the nursing student group, the presence of a substance abuse history (SAH) was sufficient to evoke suspicion of elevated levels of addiction risk in the vignette patient; however, it was not sufficient to alter mean pain congruence (PC) scores. 
Instead, both SAH and level of pain relief (PR) were significant and interacting factors influencing mean PC scores. Among the nursing students, PC scores were significantly greater in the condition in which both SAH and adequate PR were present compared with the other three conditions. Examination of the direction of the mean PC scores suggested that nursing students expected the vignette patient to overreport pain when both SAH and adequate PR were present; however, in all other conditions, they expected the patient to under-report pain. We are unaware of any available theory that can account for the interaction between patients' adequate pain relief, elevated addiction risk and expectations of overstating pain. One may speculate that, in the present study, nursing students used the level of PR as an indicator of whether addiction was developing (eg, continued presence of pain confirms the patient is not 'high', euphoric or 'seeking' drugs). In fact, the observation that nursing students expected pain to be over-reported in the adequate PR condition, whereas nonnursing students expected pain to be over-reported in the little PR condition, provided a preliminary indication that nursing trainees may have perceived the adequate PR as problematic. Although 'complete' pain relief is a desirable goal for nurses (26), it is possible that situational cues initially interpreted as a positive clinical outcome (eg, relief) may come to be understood as something more undesirable or threatening under conditions in which a substance abuse history is confirmed or suspected (eg, elation or 'high'). To illustrate this idea further, one may consider the situation in which patients with major depressive disorder are mistakenly diagnosed with bipolar disorder. Due to a longstanding depression, patients' experiences of joy are so incongruent to their longstanding depressive experience that patients' subjective reports of 'elation' may be interpreted as 'mania' by health care practitioners (31). Therefore, careful examination is required to determine whether the symptoms being reported, in fact, meet the DSM-IV criteria for mania (32).

Consistent with pain management guidelines (33), the results of the present study suggested that student nurses attended to the level of pain relief achieved in the vignette patient. The guidelines, which suggest "dosing to effect or to the point of unacceptable side effects" (33), direct health care practitioners to perform an assessment of pain relief following opioid administration. To date, there have been few studies of the expectations of health care professionals regarding the level of relief, and it is not known whether knowledge of substance abuse history would shift these expectations and/or influence decision making in clinical practice. Future research will be necessary to explore the meaning of adequate analgesia in the context of high addiction risk, and to what extent it influences current nursing practice.

To contextualize the research findings with respect to the specialized education and training experiences in the professional nursing curriculum, PC scores were also examined in undergraduate students whose area of study was unrelated to nursing. SAH and PR were significant and independent factors influencing PC scores in the non-nursing students. Mean PC ratings were similar and near zero ('congruent') when the vignette condition described adequate $\mathrm{PR}$ or no SAH. In conditions in which SAH was present or PR was little, mean PC scores were $+10 \mathrm{~mm}$ or higher in the non-nursing student group, suggesting a tendency to expect pain to be over-reported by patients. Non-nursing students estimated high levels of addiction risk (greater than 50\%) in all experimental conditions, although expectations of pain over-reporting were observed only when past (SAH) or present (experiencing little PR) behaviour were observed. As such, addiction risk did not appear to have a global and indiscriminate impact on expectations of pain over-reporting by non-nursing students, suggesting that other factors, unrelated to addiction risk, were considered in their formulation.

The objective of the present study was to examine the influence of addiction risk on undergraduate nursing trainees' perceptions of pain in a postoperative vignette patient. The use of the clinical vignette offered the benefit of shorter, intensive study and greater levels of experimental control (ie, internal validity); however, the study design was limited in terms of its generalizability or ecological validity. One advantage to the study design was the integration of concepts identified from case reports describing pseudoaddiction (17). The interpretation of the results of the study with respect to the PR variable are somewhat limited by the use of multidimensional descriptors. Although the descriptors offer a rich clinical narrative, it is not possible to conclude whether the whole description, or a particular component, was related to the study outcome. The present study design was also limited in providing information regarding the impact of expectations on actual clinical practice. Clinical decision making is a complex phenomenon (34); therefore, the identification and separation of two factors from a multifactorial and/or nonlinear system represents a significant artificial constraint. Furthermore, the vignette used in the present experimental design did not provide a pain rating from the hypothetical patient, in contrast with other vignette designs (28). Although this technique was intentionally used to elicit perceptions held by the students, this practice diverges from what nursing students may expect in clinical settings in which patients' verbal pain ratings are elicited, documented and used in the formulation (35).

Despite these study limitations, the results of the present study demonstrated that nursing students estimated a significantly lower addiction risk associated with postoperative use of opioids than students outside of the discipline. Furthermore, their estimates of addiction risk were influenced by the presence of SAH, which is consistent with current knowledge regarding addiction. In contrast, the results generate some concern about estimates of addiction risk in the general public (approximately 50\%), and suggest the continued need for reflection on how health care providers may intervene to address the acceptability of opioid treatment by patients. There was no evidence to suggest that nursing trainees' mean PC scores were significantly shifted by the higher addiction risk alone; however, in the high addiction risk conditions, the level of PR (adequate or little) experienced by the vignette patient had a significant influence on pain ratings, and pain overreporting was expected. Guidelines for opioid dosing (1) lend considerable weight to the observation of analgesic effect following opioid administration and, therefore, future research should attempt to better understand whether situational cues suggesting adequate PR (eg, comfort and relief) are imbued with new meaning (eg, high and intoxication) when addiction risk is considered more probable. 


\section{APPENDIX I}

\section{Clinical vignette*}

A 45-year old male of average weight and height, was admitted to hospital for surgical replacement of the hip joint. Pre-operative bloodwork (haematology, clinical chemistry) was normal.

\begin{tabular}{ccc} 
SAH ABSENT CONDITION & SAH PRESENT CONDITION & OR \\
"There was no prior history of substance abuse (drugs or alcohol)" & $\begin{array}{c}\text { "There is a documented history of substance abuse with drugs and } \\
\text { alcohol, including opioids." }\end{array}$ \\
\hline
\end{tabular}

The patient was admitted to the hospital the morning of the scheduled surgery, and is expected to recover on a surgical ward for up to 5 post-operative days. There were no complications with the surgery or anaesthesia. Immediately following the surgery, the patient was monitored in the post-anesthetic care unit (PACU), and, two hours later, was transferred to the hospital floor after meeting PACU discharge criteria. There were no complications noted in the PACU, and the patient's pain was treated with morphine.

During the recovery period on the hospital ward, pain was relieved using a standard dose (mg/kg) and regimen (frequency of administration) of opioid analgesics (morphine). The prescription for morphine permits an injection into the muscle at a dose of 5 mg every 4 to 6 hours as needed [5 mg I.M. q4-6h prn]. Four hours ago, the patient arrived on the hospital ward, and requested medication to relieve his pain. The nurse administered a standard dose of morphine as noted above.
ADEQUATE PAIN RELIEF CONDITION
OR
LITTLE PAIN RELIEF CONDITION

"After receiving this dose, the patient experienced adequate pain relief. He has had no difficulty sleeping and has not experienced nausea or anxiety. He did not make additional requests for pain medication".

"After receiving this dose, the patient experienced little pain relief. He has had difficulty sleeping and has experienced nausea and anxiety. He has made 2 additional requests for pain medication (none was given)." The patient is developing some pain and has now contacted the nursing staff to request a dose of morphine to relieve his pain. Please now complete the questionnaires. ${ }^{\star}$ All study participants viewed the text in plain font; bolded text shows information inserted as per randomization code. I.M. Intramuscular; prn As needed; q4-6h Every $4 \mathrm{~h}$ to $6 \mathrm{~h}$

ACKNOWLEDGEMENTS: Support for the present study was provided by a Canada Research Chair in Health Psychology and a joint infrastructure grant from the Canada Foundation for Innovation and the Ontario Innovation Trust awarded to Professor Joel Katz. Paula C Miceli is a PhD candidate at York University and was supported by a Canada Graduate Scholarship from the Canadian Institutes of Health Research at the time the present study was conducted. Ms Miceli would also like to acknowledge the additional financial support from the Canadian Federation of University Women. The authors thank Dr Colin McCartney, Sunnybrook
Health Sciences Centre (Toronto, Ontario), and Eileen Halket RNA, Department of Anesthesia and Pain Management, Toronto General Hospital (Toronto), for reviewing the clinical vignette. Special thanks are extended to Dr Robindra Sidhu, York University, for statistical consultation, Judith Hunter PhD, Assistant Professor, University of Toronto (Toronto) with early stages of study development, and to the faculty and students at the educational institutions where this research was conducted. Parts of the present article were presented at the Annual Meeting of the Canadian Pain Society, June 14-17, 2006, in Edmonton, Alberta.

\section{REFERENCES}

1. American Pain Society and American Academy of Pain Medicine. A consensus statement from the American Academy of Pain Medicine and the American Pain Society: The use of opioids for the treatment of chronic pain. Clin J Pain 1997;13:6-8.

2. Apfelbaum JL, Chen C, Mehta SS, Gan TJ. Postoperative pain experience: Results from a national survey suggest postoperative pain continues to be undermanaged. Anesth Analg 2003;97:534-40.

3. McNeill JA, Sherwood GD, Starck PL. The hidden error of mismanaged pain: A systems approach. J Pain Symptom Manage 2004;28:47-58.

4. Shirakami G, Teratani Y, Namba T, Hirakata H, Tazuke-Nishimura M, Fukuda K. Delayed discharge and acceptability of ambulatory surgery in adult outpatients receiving general anesthesia. J Anesth 2005;19:93-101.

5. Wu CL, Naqibuddin M, Rowlingson AJ, Lietman SA, Jermyn RM, Fleisher LA. The effect of pain on health-related quality of life in the immediate postoperative period. Anesth Analg 2003;97:1078-85.

6. Katz J, Jackson M, Kavanagh BP, Sandler AN. Acute pain after thoracic surgery predicts long-term post-thoracotomy pain. Clin J Pain 1996;12:50-5.

7. Botti M, Bucknall T, Manias E. The problem of postoperative pain: Issues for future research. Int J Nurs Pract 2004;10:257-63.

8. Bucknall T, Manias E, Botti M. Acute pain management: Implications of scientific evidence for nursing practice in the postoperative context. Int J Nurs Pract 2001;7:266-73.

9. Carr ECJ, Thomas VJ. Anticipating and experiencing post-operative pain: The patients' perspective. J Clin Nurs 1997;6:91-201.

10. Ferrell BR, McCaffery M, Rhiner M. Pain and addiction: An urgent need for change in nursing education. J Pain Symptom Manage 1992;7:117-24.

11. Allcock N, Toft C. Student nurses' attitudes to pain relieving drugs. Int J Nurs Stud 2003;40:125-31.

12. Allcock N, Standen P. Student nurses' experiences of caring for patients in pain. Int J Nurs Stud 2001;38:287-95.

13. Ger LP, Chang CY, Ho ST, et al. Effects of a continuing education program on nurses' practices of cancer pain assessment and their acceptance of patients' pain reports. J Pain Symptom Manage 2004:27:61-71.

14. Dewar A. Assessment and management of chronic pain in the older person living in the community. Aust J Adv Nurs 2006;24:33-8.

15. Dobscha SK, Corson K, Flores JA, Tansill EC, Gerrity MS. Veterans affairs primary care clinicians' attitudes toward chronic pain and correlates of opioid prescribing rates. Pain Med 2008;9:564-71.

16. Chapman PJ, Ganendran A, Scott RJ, Basford KE. Attitudes and knowledge of nursing staff in relation to management of postoperative pain. Aust N Z J Surg 1987;57:447-50.

17. Weissman DE, Haddox JD. Opioid pseudoaddiction - an iatrogenic syndrome. Pain 1989;36:363-6.

18. Jensen MP, Karoly P. Self-report scales and procedures for assessing pain in adults. In: Turk DC, Melzack R, eds. Handbook of Pain Assessment. New York: The Guilford Press, 2001:15-34.

19. Katz J, Melzack R. The measurement of pain. Surg Clin North Am 1999;79:231-52.

20. Bergh I, Sjostrom B. A comparative study of nurses' and elderly patients' rating of pain and pain tolerance. J Gerontol Nurs 1999;25:30-6.

21. Bowman JM. Perception of surgical pain by nurses and patients. Clin Nurs Res 1994:3:69-76.

22. American Psychiatric Association. Diagnostic and Statistical Manual of Mental Disorders, 4th edn. Washington, DC: American Psychiatric Publishing Inc, 1994.

23. Tabachnick BG, Fiddell LS. Using Multivariate Statistics. Toronto: Allyn and Bacon, 2001.

24. Merskey H, Albe-Fessard DG, Bonica JJ, et al. IASP Sub-committee on taxonomy. Pain 1979;6:249-55. 
25. Craig KD. Pain in infants and children: Sociodevelopmental variations on the theme. In: Giamerardino MA, ed. Pain 2002 An Updated Review. Seattle: IASP Press, 2002:305-14.

26. Winefield HR, Katsikitis M, Hart LM, Rounsefell BF. Post-operative pain experiences: Relevant patient and staff attitudes. J Psychosom Res 1990;34:543-52.

27. Nash R, Yates P, Edwards H, et al. Pain and the administration of analgesia: What the nurses say. J Clin Nurs 1999;8:180-9.

28. McCaffery M, Rolling Ferrell B, Pasero C. Nurses' personal opinions about patients' pain and their effect on recorded assessments and titration of opioid doses. Pain Manage Nurs 2000;1:79-87.

29. Passik SD, Kirsh KL. A pilot survey of aberrant drug-taking attitudes and behaviours in samples of cancer and AIDS patients. J Pain Symptom Manage 2000;19:274-86.

30. Gunnarsdottir S, Donovan HS, Serlin RC, Voge C, Ward S. Patient-related barriers to pain management: The Barriers Questionnaire II (BQ-II). Pain 2002;99:385-96.
31. Parker G, Hadzi-Pavlovic D, Tully L. Distinguishing bipolar and unipolar disorders: An isomer model. J Affect Disord 2006;96:67-73

32. Ramsley S. Unipolar or bipolar depression? Improving diagnostic confidence with the adult patient. J Am Acad Nurse Pract 2007;19:172-8.

33. Jovey RD, Ennis J, Gardner-Nix J, et al. Use of opioid analgesics for the treatment of chronic non-cancer pain - a consensus statement and guidelines from the Canadian Pain Society. Pain Res Manage 2003;8(Suppl A):3A-14A.

34. Green CR, Wheeler JRC, LaPorte F. Clinical decision making in pain management: Contributions of physician and patient characteristics to variations in practice. J Pain 2003;4:29-39.

35. Agency for Health Care Policy and Research. Acute pain management in adults: Operative procedures. Quick reference guide for clinicians. Rockville, MD: AHCPR Publication No. 92-0019; 1992. 


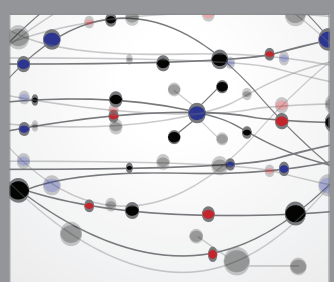

The Scientific World Journal
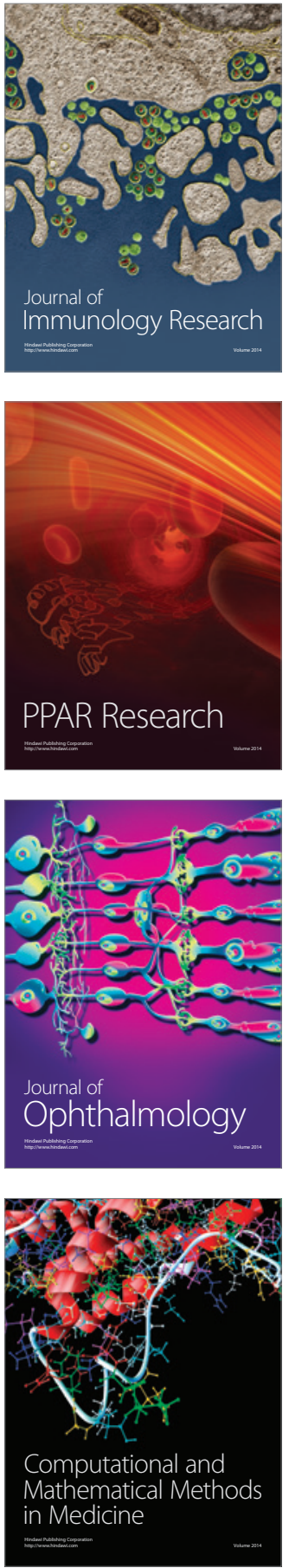

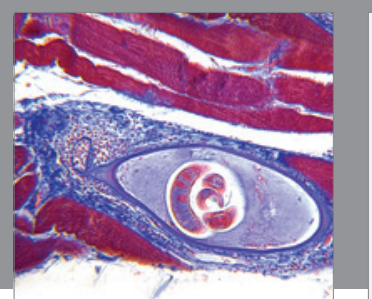

Gastroenterology Research and Practice

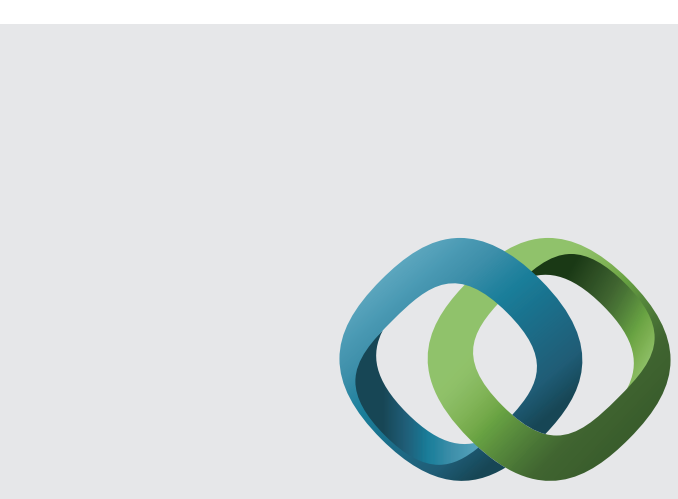

\section{Hindawi}

Submit your manuscripts at

http://www.hindawi.com
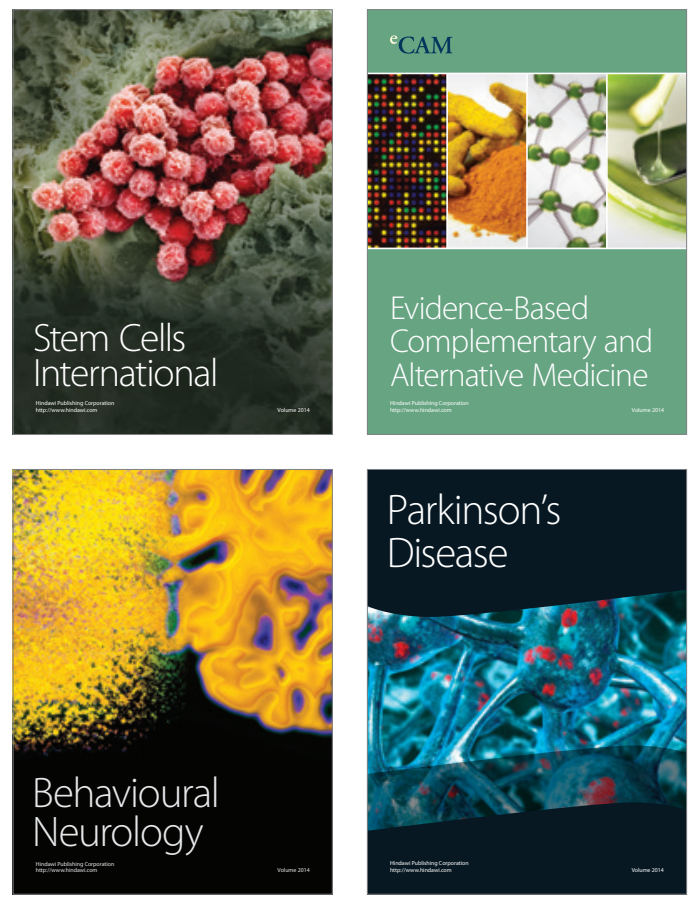
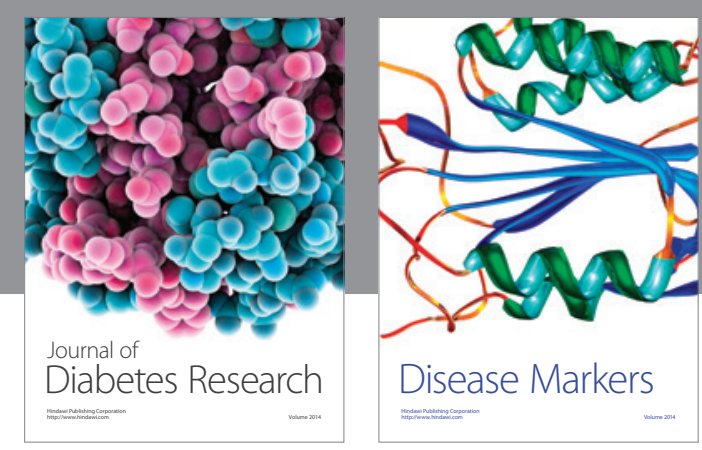

Disease Markers
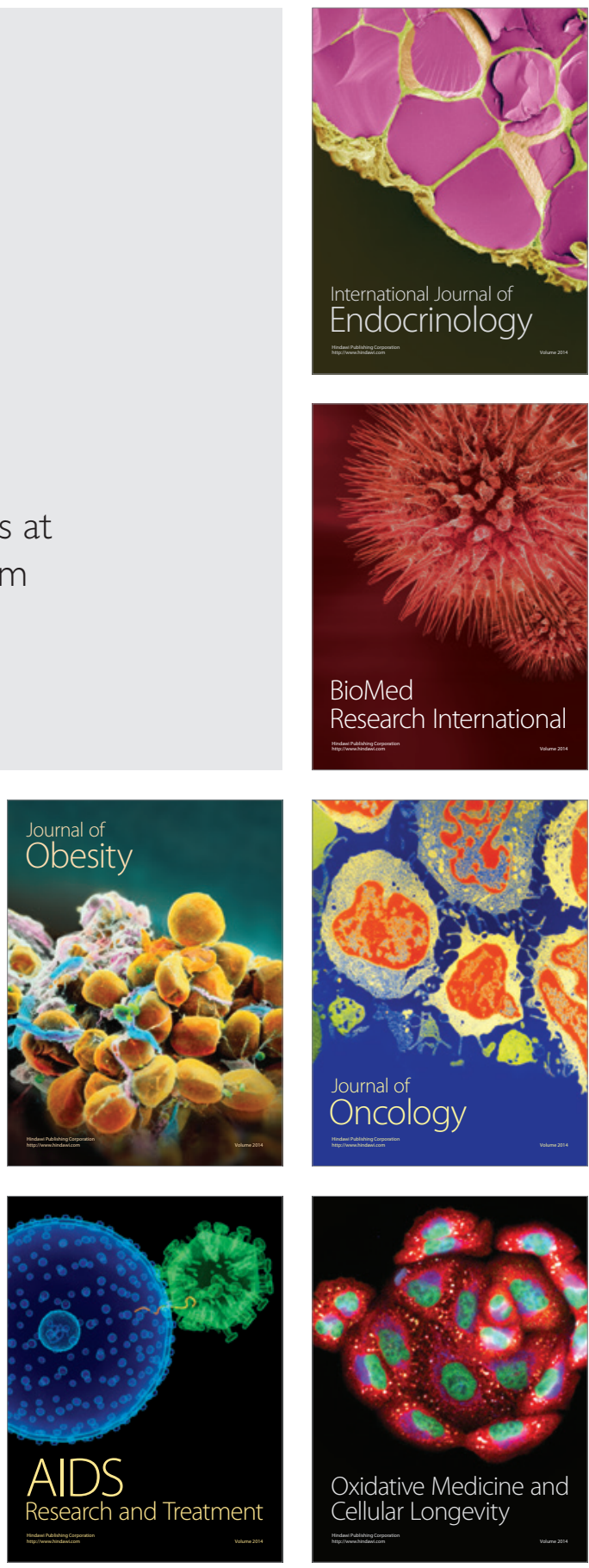